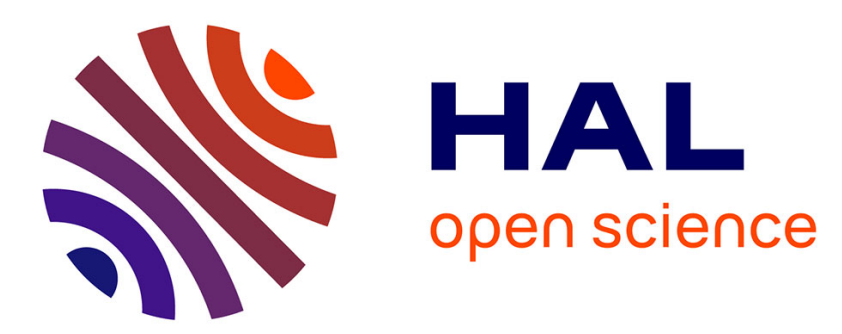

\title{
The Aspect Hypothesis, the comparative fallacy and the validity of obligatory context analysis: a reply to Lardiere, 2003 \\ Yasuhiro Shirai
}

\section{- To cite this version:}

Yasuhiro Shirai. The Aspect Hypothesis, the comparative fallacy and the validity of obligatory context analysis: a reply to Lardiere, 2003. Second Language Research, 2007, 23 (1), pp.51-64. $10.1177 / 0267658307071602$. hal-00570721

\section{HAL Id: hal-00570721 \\ https://hal.science/hal-00570721}

Submitted on 1 Mar 2011

HAL is a multi-disciplinary open access archive for the deposit and dissemination of scientific research documents, whether they are published or not. The documents may come from teaching and research institutions in France or abroad, or from public or private research centers.
L'archive ouverte pluridisciplinaire HAL, est destinée au dépôt et à la diffusion de documents scientifiques de niveau recherche, publiés ou non, émanant des établissements d'enseignement et de recherche français ou étrangers, des laboratoires publics ou privés. 


\section{The Aspect Hypothesis, the comparative fallacy and the validity of obligatory context analysis: a reply to Lardiere, 2003}

Yasuhiro Shirai University of Pittsburgh

Lardiere (2003), in her reply to Lakshmanan and Selinker (2001), justifies the use of suppliance in obligatory contexts as a method of analysis in the investigation of the second language (L2) acquisition of past tense, and claims that such a method is characteristic of previous studies that have proposed the Aspect Hypothesis. It is argued here that this is a misrepresentation of research on the Aspect Hypothesis which, contra Lardiere, takes seriously the problem of the 'comparative fallacy' and the autonomous nature of interlanguage. Lardiere also argues that the Aspect Hypothesis studies suffer from a different kind of comparative fallacy, to which I reply by discussing the importance of refining methods of analysis in verb aspectual classification of learner data.

\section{Introduction}

Lardiere (2003) provides an important discussion of the Aspect Hypothesis and the Discourse Hypothesis in reply to Lakshmanan and Selinker's (2001) comments on her earlier work (Lardiere, 1998). Lakshmanan and Selinker suggested that the lack of past tense marking in obligatory contexts in Lardiere's fossilized informant (Patty) may be due to the possibility that Patty was not marking past tense as the native speaker's grammar would posit, but rather was marking 'telicity' and 'foregrounding', as has been found in the previous research on past tense marking in second language acquisition (SLA). Lardiere (2003)

Address for correspondence: Yasuhiro Shirai, Department of Linguistics, 2806 Cathedral of Learning, University of Pittsburgh, Pittsburgh, PA 15260, USA; email: yshirai@ pitt.edu 
reported the analysis of her data, and showed that Patty's past tense marking is not constrained by inherent aspect or discourse grounding. That is, there is no correlation between past tense marking and telicity or foregrounding in Patty's data, contrary to the predictions of the Aspect Hypothesis (Andersen and Shirai, 1994) and the Discourse Hypothesis (Bardovi-Harlig, 1995).

Lardiere's response is convincing in showing that Patty's past tense marking is not governed by lexical aspect or grounding, thus effectively refuting Lakshmanan and Selinker's specific hypotheses concerning her data - as far as past tense marking used in obligatory contexts is concerned. However, she did not adequately address the important question of the comparative fallacy, originally formulated for second language (L2) acquisition research by Bley-Vroman (1983). The crux of Bley-Vroman's argument was that L2 researchers should respect the autonomous nature of the learner's language, because it is often missed by researchers, who tend to take target language perspectives in analysing learner data. Looking only at obligatory context is, by definition, a method of analysis that commits the comparative fallacy. Lardiere also extensively discusses methodological problems concerning studies of the Aspect Hypothesis and argues that the comparative fallacy is involved in those studies.

In this reply, I show that contrary to Lardiere's characterization, the Aspect Hypothesis studies do not restrict analysis to obligatory contexts for the target forms, and do take the autonomous nature of interlanguage seriously, and that the comparative fallacy that may have been involved in the Aspect Hypothesis studies that Lardiere identified does not justify confining analysis to obligatory contexts, a strategy which necessarily increases the risk of the comparative fallacy. I understand that it was not Lardiere's intention to argue against the empirical basis of the Aspect Hypothesis, but nevertheless it is important to clarify some apparent misunderstandings concerning the Aspect Hypothesis - both its goals and methodology - and furthermore to question the validity of a method based on obligatory context analysis.

\section{Obligatory context analysis and the Aspect Hypothesis: setting the record straight}

Lardiere (2003: 135-36) characterizes the Aspect Hypothesis (henceforth, AH) studies as being concerned mainly with obligatory 
context, but this characterization is not accurate. Rather, the AH studies specifically target the form-meaning correlation, as summarized below (Bardovi-Harlig, 2000, originally proposed in Shirai, 1991: 9-10; see also Andersen and Shirai, 1996: 533; Bardovi-Harlig and Bergström, 1996: 312; Bardovi-Harlig, 1999: 359):

1) Learners first use (perfective) past marking on achievements and accomplishments, eventually extending use to activities and statives.

2) In languages that encode the perfective/imperfective distinction, imperfective past appears later than perfective past, and imperfect past marking begins with statives, extending next to activities, then to accomplishments, and finally to achievements.

3) In languages that have progressive aspect, progressive marking begins with activities, then extends to accomplishments and achievements.

4) Progressive markings are not incorrectly overextended to statives.

(Bardovi-Harlig, 2000: 227)

Note that there is no mention of the obligatory context in BardoviHarlig's generalizations, except in (4), which neither Lakshmanan and Selinker nor Lardiere touch upon. ${ }^{1}$ Whether obligatory context or not, the hypotheses (1) to (3) predict strong correlations between lexical aspect and the use of tense-aspect morphology.

Despite this, Lardiere states:

Not only would altering the set of obligatory contexts in the way suggested by Lakshmanan and Selinkes have drastically impaired compatibility with the "functional category literature', but it would misrepresent the Aspect Hypothesis literature as well. (Lardiere, 2003: 136)

However, Lakshmanan and Selinker are not necessarily off the mark. The strongest prediction of the AH is $100 \%$ correlation between morphology and lexical aspect. Shirai (1991, also Shirai and Andersen,

\footnotetext{
${ }^{1}$ Even here we should be careful about the use of 'incorrectly'. As is often pointed out, stative progressive is possible with stative verbs, and it is not easy to draw the line between correct and incorrect uses. Furthermore, this pattern does not always hold for L2 (Andersen and Shirai, 1994). (Hypothesis (4) was originally proposed for L1 data by Bickerton (1981) and others, and was summarized in Shirai (1991). In fact, Shirai's (1994) study falsified this hypothesis for L1 acquisition.)
} 
1995) showed that more than $95 \%$ of past tense marking is on achievement verbs at the earliest stage of first language (L1) acquisition of English in conversational interaction. Note that in this study there was no coding of obligatory context done.

The discussion of obligatory contexts by Andersen and Shirai (1994: 143, quoted in Laridere, 2003: 136) was intended to address the doubts ${ }^{2}$ of sceptics who suggest that strong form-meaning correlations are merely due to discourse context (e.g. punctual actions are almost always finished when you want to talk about them) and do not reflect learners' lack of competence. If one can show that learners tend to delete past marking or progressive marking in obligatory contexts, it shows that the strong correlation comes not just from discourse context, but also from the learner's 'inability' (i.e. their linguistic ability differs from that of adult native speakers). It is for this reason that Andersen and Shirai emphasized the more frequent omission of past marking for atelic verbs in obligatory past context. ${ }^{3}$

Three major types of data-elicitation methods have been used to investigate the AH in L2 acquisition: (1) narratives, (2) paper-andpencil tests, (3) conversational interaction (for a comprehensive list, see Bardovi-Harlig, 1999: 354-55). Narratives consist mostly of 3rd person narrative such as film retelling (e.g. Bardovi-Harlig, 1998), but personal narratives have also been used (e.g. López-Ortega, 2000). Since narratives mostly recount past events, these studies may seem like they are focusing on obligatory contexts. But as far as I know, these narrative studies do not specifically emphasize the obligatory nature of their verbal contexts. This is only natural because it is very difficult to claim that past narratives have to be told in past tense, given that native speakers often employ the conversational historical present, and given that the conditions under which tense-shifting in narrative occurs are still

${ }^{2}$ This doubt often comes in the context of L1 acquisition. For example, Weist (1989) made such an argument to account for skewed distribution in the use of tense-aspect morphology in Polish.

${ }^{3}$ This is clear from the discussion in Andersen and Shirai (1994: 144):

Most of the studies that argue for the aspect hypothesis do not report the pattern of the lack of marking in obligatory contexts ... However, as already reviewed, some L2 acquisition studies clearly have shown that stative verbs receive past marking in obligatory-past contexts less frequently than accomplishment/achievement verbs ... In this sense, first and second language learners do things differently ... from adult native speakers, and the deviant behavior appears to be guided by the aspectual classes of verbs. 
unknown. There may also be crosslinguistic variation: it is natural for Spanish native speakers to tell a $3 r d$ person narrative in the present tense, rather than in the past tense (Salaberry, 1999: 173-74). Indeed, one wonders what the obligatory past contexts are for past narratives. ${ }^{4}$

The paper-and-pencil tests, on the other hand, have a much better chance of clearly determining the obligatory contexts for tense-aspect markers and, indeed, many studies strive to create such contexts, although this is not always easy. ${ }^{5}$ Even so, paper-and-pencil tests (e.g. rational cloze tests; Bardovi-Harlig and Reynolds, 1995; Collins, 2002; 2004) are in line with Lardiere's characterization of the AH studies as focusing on obligatory contexts.

The last type of data - conversational interaction - disconfirms Lardiere's characterization of the AH studies. Lardiere states in a footnote (p. 136) that 'Robison (1995) is an exception in that he looked at the use of verbal morphology across other temporal contexts (such as present and future) as well', but Bardovi-Harlig's (1999) list of AH studies include many more exceptions: Housen $(1993 ; 1994)$ on Dutch; Robison (1990), Rohde (1996) on English, Shirai and Kurono (1998: Study 1) on Japanese; Andersen (1991) on Spanish. There are more recent studies on English: Bayley, 1999; Lee, 2001; Gavruseva, 2002; Housen, 2002; Rohde, 2002. It is important to point out that only one of these studies (Rohde, 2002) reports an obligatory context analysis, and that it does not restrict the analysis to obligatory contexts (i.e. it offers an obligatory context analysis in addition to a form-meaning analysis that includes all the uses of morphological form in question).

It is important to set the record straight, since Lardiere's characterization of the AH studies as mainly concerned with obligatory contexts is anything but a trivial misunderstanding. The study of the AH in L2 was started by Roger Andersen and his students at UCLA in the 1980s, who

\footnotetext{
${ }^{4}$ Although Lardiere (2003: 136) refers readers to Bardovi-Harlig (2000: 229-30) to support her characterization of the $\mathrm{AH}$ as mainly concerned with obligatory context, the relevant chapter of Bardovi-Harlig (2000; i.e. chapter 4 on the AH) never used the term 'obligatory'. Perhaps Lardiere interpreted Bardovi-Harlig's use of 'past-time' contexts as obligatory contexts, but they are not the same thing.

${ }^{5}$ Bardovi-Harlig and Reynolds (1995), for example, had a native speaker control group take the cloze type test, and they did not always agree on their judgements.
} 
took the autonomous nature of interlanguage seriously, as reflected in many early unpublished papers listed in Andersen and Shirai (1996). This research was extended by Kathleen Bardovi-Harlig and her students in the 1990s, who used narrative data and paper-and-pencil tests. But never did the research at any point restrict its focus to obligatory contexts, and the fundamental question has always been how learners establish form-meaning mappings. In order to establish the pattern of form-meaning mapping independently of the target language, it is absolutely necessary to include all the uses of a form by the learner regardless of its meaning or context, and then start from there. ${ }^{6}$

As is well known, during the 1970s the study of SLA moved away from obligatory context analysis because it is not very helpful if we want to characterize a learner's interlanguage independently of the target language (e.g. Larsen-Freeman and Long, 1990; Ellis, 1994). Huebner $(1979 ; 1983)$ clearly showed that obligatory context analysis gives us an incorrect picture of the learner's interlanguage system.

Another, related, move away from obligatory context analysis in the 1970s and 1980s was the method of analysis employed in the morpheme acquisition studies. As is often the case with many SLA studies, the early morpheme studies imported methods and research questions from first language acquisition research (e.g. Dulay and Burt, 1974). The SOC (supplied in obligatory context) analysis was one such method (Brown, 1973). The ratio of morphemes supplied in obligatory context was used to measure the learner's level of mastery of various morphemes. However, this method did not accurately represent the accuracy of L2 learners' speech, because L2 learners exhibit overuse of grammatical morphemes much more frequently than L1 children. For example, Wagner-Gough (1978) reported on an ESL learner (L1 Persian) who overused -ing to almost any context. In such cases, SOC would be very high, despite the very frequent overuse of -ing. To alleviate this problem, TLU (Target-Like Use; Stauble; 1981; 1984; Pica, 1983) ${ }^{7}$ was introduced.

\footnotetext{
${ }^{6}$ As an anonymous reviewer correctly points out, ideally, one should look at not just the form in question (in this case, past tense), but also other verb forms (e.g. present, progressive, 3rd singular $-s$, etc.) to capture the total system.

${ }^{7}$ Hakuta (1976) was the first to deal with the problem of overuse: He calculated the 'proportion of correct usage over total usage' (Hakuta 1976: 340) of a particular morpheme, which is different from Stauble's and Pica's TLU.
} 
Such development in the history of SLA research methodology indicates that restricting the analysis to obligatory context runs the risk of missing the total picture of learner language. Overuse of morphemes by L2 learners, which forced L2 researchers to invent a different analytical method, makes it more important in L2 than in L1 research ${ }^{8}$ to take the comparative fallacy seriously. The only way to avoid the comparative fallacy in morpheme acquisition studies is to look at all uses of the linguistic form being investigated: and even then the comparative fallacy is hard to avoid, since our analysis is always coloured by the target norm. ${ }^{9}$

I am not suggesting here that Lardiere would find different results if she looked at all the uses of past tense marking (though she might). In fact there seems to be an asymmetry between past tense marking and progressive marking; the overuse of past tense is relatively not very frequent (Housen, 2000; Ionin and Wexler, 2002). However, its overuse has been reported in the AH literature. Robison (1995), for example, suggests that L2 learners, especially at early stages, use past tense marking in non-past contexts:

Perhaps more significantly, much of the PAST marking on punctual events occurs in non-anterior context ... In fact, half of Group I's [lowest proficiency group] PAST punctual event tokens appear in non-anterior contexts. (Robison, 1995:358)

More specifically, Robison (1995: 362) reports that the use of past tense forms in non-past contexts decreases as the learner's proficiency increases $(47.6 \% \rightarrow 24.8 \% \rightarrow 23.0 \% \rightarrow 16.1 \%)$. At the lowest level, almost $50 \%$ of past tense forms are used in non-past contexts. Even at the highest level, the learners' (in this case, first year students at the University of Puerto Rico) use of past tense for non-past reference is substantial (16.1\%). Depending on Patty's level of interlanguage, it is possible that Lardiere's analysis', restricted to obligatory past context, may be missing many instances of past tense marking, and this needs to

${ }^{8}$ Overuse (i.e. errors of commission) is not very common in L1 English data (Brown, 1973), since English allows for default zero forms both in nouns and verbs. This is not the case in other languages where unaffixed forms are not possible (e.g. verbal inflection in Turkish and Japanese).

${ }^{9}$ It should be noted here that TLU analysis also hinges on the notion of 'obligatory context' and is also based on a comparison with the target norm and thus prone to the comparative fallacy. But the fundamental difference between the SOC and TLU analysis is that the latter is committed to looking at all the uses of forms, thus trying to capture the total picture of interlanguage. 
be tested. Although Patty's grammar may be considered as a final state, that does not mean her grammar is native-like, obviously, given the low suppliance rate of her past tense marking (34\%). This is an empirical question that can only be answered by actually looking at the data in non-obligatory contexts as well.

In sum, in order to avoid the comparative fallacy problem, it is imperative, methodologically speaking, to look at the total use of a particular morpheme, not just obligatory contexts. This is not incompatible with obligatory context analysis: one can do an obligatory-context analysis ${ }^{10}$ and, in addition, can look at the total system.

\section{The comparative fallacy in the Aspect Hypothesis studies?}

Lardiere argues that the AH studies suffer from a different kind of comparative fallacy. Her point is that AH studies, by using Vendlerean linguistic tests to classify verbs, assume more semantic representation on the part of the learner than warranted. When a learner says, 'walk' there is no guarantee that the learner has the same semantic representation as that of native speakers. Indeed, they might have been using it with an inchoative meaning, as in 'start to walk'. This is an important methodological and theoretical issue that needs to be addressed in L2 aspect research.

Theoretically, it is important in relation to crosslinguistic influence in the acquisition of tense-aspect morphology. As Lardiere notes, L2 learners, unlike L1 children, 'bring to the SLA task their own fully developed set of 'features' for organizing tense and/or aspect' (p. 138). The AH studies so far have not paid much attention to the effect of the L1 (but see Housen, 2002; Collins, 2002; 2004; Rocca, 2002; Gabriele et al., 2003), placing more emphasis on the universal aspects of tense-aspect acquisition. This in fact is a historical accident, and the field is now ripe for inquiries into this important area.

To test the effect of the L1, one needs to carefully examine the lexical aspect and grammatical aspect/tense in both target and source languages. Shirai and Nishi (2002) systematically compared how English and Japanese differ in their lexicalization of verbal concepts

\footnotetext{
${ }^{10}$ As noted above, obligatory analysis can be sometimes useful to investigate what learners 'can' do, rather than what learners 'do' do.
} 
and pointed out that lexical equivalents do not always have the same inherent aspect. For example, know is a stative verb whereas sit and stand are activities in English, but their counterparts in Japanese are all achievements. Nishi and Shirai (2004) further tested how these discrepancies in L1 and L2 structures affect L2 acquisition of the Japanese aspect marker -teiru by native English speakers, and found clear effects of L1-L2 mapping on learners' acceptability judgement scores.

As Lardiere noted, the contribution of generative L2 research in recent years to the understanding of conditions on semantic transfer has been substantial, and the area of tense-aspect is no exception. For example, Slabakova and Montrul (2002) and Gabriele et al. (2003), using entailment tests involving imperfective aspect with telic vs. atelic verbs, investigated English speakers' acquisition of aspectual interpretation in Spanish and Japanese, respectively.

Methodologically, it is important to note that many of these studies that addressed the L1 effect in the acquisition of aspect used controlled experiments. This is because only in controlled experiments can we manipulate complex interactions between L1 and L2 aspectual structures. If we use natural production data, such manipulation would be very difficult, if not impossible. Furthermore, the interpretation of the speaker's intended meaning is not easy.

So, what should we do to address the problem pointed out by Lardiere in verb classification in learner language? My position is this: since we cannot be sure about learners' intentions or their semantic representations, it is probably more reasonable to be agnostic about them to some degree. But at the same time we need rigour in classification to ensure some level of replicability across studies. ${ }^{11}$ Thus I treat classification as a kind of operational definition that helps us see the tendencies in the use of tense-aspect markers in relation to verb semantics, without assuming that learners have such semantic representation.

Lardiere suggests that Shirai and Andersen's discussion of this point is 'meagre' (p. 139), ${ }^{12}$ but this 'meagreness' is a direct consequence of

\footnotetext{
${ }^{11}$ To enhance replicability, other researchers have used Shriai \& Andersen's tests to analyse their own data (e.g. Weist et al. 2004; Gavruseva, 2002; 2004). The tests have also been applied, with minimal modifications, to other languages such as Turkish (Aksu-Koç, 1998) and Spanish (Salaberry, 1999). ${ }^{12}$ Despite Lardiere's criticism of the methodology of the AH studies, there was no description of how she classified verb tokens into telic vs. atelic predicates.
} 
dealing with the difficulty of interpreting learner data, i.e. the need to guard against 'overinterpreting' learner utterances. Moreover, in my previous research dealing with conversational data (Shirai, 1991; 1993; 1998; Shirai and Kurono, 1998), I have always excluded cases where it is not possible to determine inherent aspect. Lardiere discusses several examples of cases that are difficult to interpret in her data (p. 137), and I would probably exclude many of them from quantitative analysis. There is a fine line between maintaining methodological rigour and avoiding overinterpretation. Our task is to maximize methodological rigour by using replicable methods of analysis, while maximizing approximate understanding in attempting to characterize learner language.

In sum, Lardiere's methodological criticism of the AH studies needs to be addressed at two levels:

1) the $\mathrm{AH}$ studies should investigate the effect of L1 semantics more seriously, and this requires experimental, controlled data; and

2) in the analysis of production data, one should attempt maximum rigour in classification without reading in too much about learners' semantic representation.

\section{Conclusions}

Throughout her reply to Lakshmanan and Selinker, Lardiere repeatedly emphasizes the importance of researchers being aware of the comparative fallacy. But nowhere in her reply does she present sufficient justification for not looking at use of past tense inflections in non-obligatory contexts. Citing obligatory context analysis as the typical method used in previous research within the $\mathrm{AH}$ framework does not constitute such a justification, especially given that looking at non-obligatory use is not incompatible with obligatory context analysis (i.e. one can do both). Pointing out that the Aspect Hypothesis studies might be susceptible to a different kind of comparative fallacy does not alleviate the problem, either.

On the other hand, I welcome Lardiere's reanalysis of her data, and her critique of the $\mathrm{AH}$, because the acquisition of past tense inflection has been an important domain of inquiry for both the $\mathrm{AH}$ and generative research. During the past 20 years or so, generative studies on interlanguage have amassed an extensive body of research that has 
uncovered many aspects of second language grammar acquisition (Hawkins, 2001; White, 2003), including the acquisition of past tense inflection. Despite the overlap in the target phenomenon, however, the two approaches have virtually ignored each other (but see Gavruseva, $2002 ; 2003 ;$ 2004). Needless to say, for learners facing the task of past tense acquisition, it is one and only one phenomenon. A dialogue of this nature between two different paradigms, I believe, will eventually result in a better understanding of past tense acquisition.

\section{Acknowledgements}

I thank Kevin Gregg, Yoshinori Sasaki, the students of his seminar at Ochanomizu university and four anonymous Second Language Research reviewers for their helpful comments on an earlier version of this reply. Thanks also go to Roger Andersen for valuable discussion about the history of the TLU analysis. All the remaining shortcomings are mine. The writing of this article is partially supported by grants from the Japan Society for the Promotion of Science (No. 13410034, PI: Kiyoshi Otomo, and No. 14580326, PI: Yoshinori Sasaki).

\section{References}

Aksu-Koç, A. 1998: The role of input vs. universal predispositions in the emergence of tense-aspect morphology: evidence from Turkish. First Language 18, 255-80.

Andersen, R.W. 1991: Developmental sequences: the emergence of aspect marking in second language acquisition. In Huebner, T. and Ferguson, C.A. editors, Crosscurrents in second language acquisition and linguistic theories. John Benjamins, 305-24.

Andersen, R.W. and Shirai, Y. 1994: Discourse motivations for some cognitive acquisition principles. Studies in Second Language Acquisition 16, 133-56. 1996: Primacy of aspect in first and second language acquisition: the pidgin/creole connection. In Ritchie, W.C. and Bhatia, T.K., editors, Handbook of second language acquisition. Academic Press, 527-70.

Bardovi-Harlig, K. 1995: A narrative perspective on the development of the tense/aspect system in second language acquisition. Studies in Second Language Acquisition 17, 263-91.

1998: Narrative structure and lexical aspect: conspiring factors in second language acquisition of tense-aspect morphology. Studies in Second Language Acquisition 20, 471-508. 
1999: From morpheme studies to temporal semantics: tense-aspect research in SLA. Studies in Second Language Acquisition 21, 341-82. 2000: Tense and aspect in second language acquisition: form, meaning, and use. Blackwell.

Bardovi-Harlig, K. and Bergström, A. 1996: The acquisition of tense and aspect in SLA and FLL: a study of learner narratives in English (SL) and French (FL). Canadian Modern Language Review 52, 308-30.

Bardovi-Harlig, K. and Reynolds, D.W. 1995: The role of lexical aspect in the acquisition of tense and aspect. TESOL Quarterly 29, 107-31.

Bayley, R. 1999: The primacy of aspect hypothesis revisited: evidence from Language Shift. Southwest Journal of Linguistics 18, 1-22.

Bickerton, D. 1981: The roots of language. Karoma.

Bley-Vroman, R. 1983: The comparative fallacy in interlanguage studies: the case of systematicity. Language Learning 33, 1-17.

Brown, R. 1973: A first language: the early stages. Harvard University Press.

Collins, L. 2002: The roles of L1 influence and lexical aspect in the acquisition of temporal morphology. Language Learning 52, 43-94.

_ 2004: The particulars on universals: a comparison of the acquisition of tense-aspect morphology among Japanese and French-speaking learners of English. The Canadian Modern Language Review 61, 251-74.

Dulay, H.C. and Burt, M. 1974: Natural sequences in child second language acquisition. Language Learning 24, 37-53.

Ellis, R. 1994: The study of second language acquisition. Oxford University Press.

Gabriele, A., Martohardjono, G. and McClure, W. 2003: Why swimming is just as difficult as dying for Japanese learners of English. In Bittner, D. and Gagarina, N., editors, ZAS Papers in Linguistics 29: Acquisition of Aspect, ZAS, 85-103.

Gavruseva, E. 2002: Is there primacy of aspect in child L2 English? Bilingualism: Language and Cognition 5, 109-30.

- 2003: Aktionsart, aspect, and the acquisition of finiteness in early child grammar. Linguistics 41, 723-55.

— 2004: Root infinitives in child second language English: an aspectual features account. Second Language Research 20, 335-71.

Hakuta, K. 1976: A case study of a Japanese child learning English as a second language. Language Learning 26, 321-51.

Hawkins, R. 2001: Second language syntax: a generative introduction. Blackwell.

Housen, A. 1993: L2 acquisition of verb morphology: a case study. In Kettermann, B. and Wieden, W., editors, Current issues in European second language acquisition research. Gunter Narr, 195-212.

- 1994: Tense and aspect in second language acquisition: the Dutch interlanguage of a native speaker of English. In Vet, C. and Vetters, V., editors, Tense and aspect in discourse. Mouton de Gruyter, 257-91. 
2000: Verb semantics and the acquisition of tense-aspect in L2 English. Studia Linguistica 54, 249-59.

2002: The development of tense-aspect in English as a second language and the variable influence of inherent aspect. In Salaberry, R. and Shirai, Y., editors, The L2 acquisition of tense-aspect morphology. John Benjamins, $155-97$.

Huebner, T. 1979: Order-of-acquisition vs. dynamic paradigm: a comparison of method in interlanguage research. TESOL Quarterly 13, 21-8. 1983: A longitudinal analysis of the acquisition of English. Karoma.

Ionin, T. and Wexler, K. 2002: Why is 'is' easier than '-s'? Acquisition of tense/agreement morphology by child second language learners of English. Second Language Research 18, 95-136.

Lakshmanan, U. and Selinker, L. 2001: Analyzing interlanguage: how do we know what learners know? Second Language Research 17, 393-420.

Lardiere, D. 1998: Case and tense in the 'fossilized' steady state. Second Language Research 14, 1-26.

2003: Revisiting the comparative fallacy: a reply to Lakshmanan and Selinker, 2001. Second Language Research 19, 129-43.

Larsen-Freeman, D. and Long, M.H. 1990: An introduction to second language acquisition research. Longman.

Lee, E.J. 2001: Interlanguage development by two Korean speakers of English with a focus on temporality. Language Learning 51, 591-633.

López-Ortega, N. 2000: Tense, aspect, and narrative structure in Spanish as a second language. Hispania 83, 488-502.

Nishi, Y. and Shirai, Y. 2004: Where L1 semantic transfer occurs: the significance of cross-linguistic variation in lexical aspect in the universal phenomena of L2 aspect acquisition. Paper presented at the Conference on diversity and universals in language: the consequences of variation, Stanford University, May 21-23. To appear in Matsumoto, Y., Oshima, D.Y., Robinson, O. and Sells, P., editors, Diversity in language: perspectives and implications. CSLI Publications.

Pica, T. 1983: Adult acquisition of English as a 2nd language under different conditions of exposure. Language Learning 33, 465-97.

Robison, R.E. 1990: The primacy of aspect: aspectual marking in English interlanguage. Studies in Second Language Acquisition 12, 315-30. 1995: The aspect hypothesis revisited: a cross-sectional study of tense and aspect marking in interlanguage. Applied Linguistics 16, 344-70.

Rocca, S. 2002: Lexical aspect in child second language acquisition of temporal morphology: a bidirectional study. In Salaberry, R. and Shirai, Y., editors, The L2 acquisition of tense-aspect morphology. John Benjamins, $245-80$.

Rohde, A. 1996: The aspect hypothesis and the emergence of tense distinctions in naturalistic L2 acquisition. Linguistics 34, 1115-37. 
2002: The aspect hypothesis in naturalistic acquisition: what uninflected and non-target-like verb forms in early interlanguage tell us. In Salaberry, R. and Shirai, Y., editors, The L2 acquisition of tense-aspect morphology, 199-220. John Benjamins.

Salaberry, R. 1999: The development of past tense verbal morphology in classroom L2 Spanish. Applied Linguistics 20, 151-78.

Shirai, Y. 1991: Primacy of aspect in language acquisition: simplified input and prototype. Unpublished $\mathrm{PhD}$ dissertation, University of California, Los Angeles.

- 1993: Inherent aspect and the acquisition of tense/aspect morphology in Japanese. In Nakajima, H. and Otsu, Y., editors, Argument structure: its syntax and acquisition. Kaitakusha, 185-211.

— 1994: On the overgeneralization of progressive marking on stative verbs: bioprogram or input? First Language 14, 67-82.

— 1998: The emergence of tense-aspect morphology in Japanese: universal predisposition? First Language 18, 281-309.

Shirai, Y. and Andersen, R.W. 1995: The acquisition of tense/aspect morphology: a prototype account. Language 71, 743-62.

Shirai, Y. and Kurono, A. 1998: The acquisition of tense/aspect marking in Japanese as a second language. Language Learning 48, 245-79.

Shirai, Y. and Nishi, Y. 2002: Lexicalization of aspectual structures in English and Japanese. In Giacalone Ramat, A., editor, Typology and second language acquisition. Mouton de Gruyter, 267-90.

Slabakova, R. and Montrul, S. 2002: On viewpoint aspect interpretation and its L2 acquisition. In Salaberry, R. and Shirai, Y., editors, The L2 acquisition of tense-aspect morphology, John Benjamins, 323-95.

Stauble, A.M. 1981: A comparison of a Spanish-English and JapaneseEnglish second language continuum: verb phrase morphology. Paper presented at the first Europe-North American workshop on crosslinguistic second language acquisition research. Cited in Pica, 1983.

— 1984: A comparison of the Spanish-English and Japanese-English interlanguage continuum. In Andersen, R.W., editor, Second language: a crosslinguistic perspective. Newbury House, 323-53.

Wagner-Gough, J. 1978: Comparative studies in second language learning. In Hatch, E.M., editor, Second language acquisition: a book of readings. Newbury House, 155-71.

Weist, R.M. 1989: Aspects of the roots of language: commentary on Cziko. First Language 9, 45-9.

Weist, R.M., Pawlak, A. and Carapella, J. 2004: Syntactic-semantic interface in the acquisition of verb morphology. Journal of Child Language 31, 31-60.

White, L. 2003: Second language acquisition and universal grammar. Cambridge University Press. 